\title{
Urgences
}

\section{Sept fantômes de l'Hôtel Manoir}

\section{Alain Blanchet}

Numéro 5, 3e trimestre 1982

URI : https://id.erudit.org/iderudit/025073ar

DOI : https://doi.org/10.7202/025073ar

Aller au sommaire du numéro

Éditeur(s)

Urgences

ISSN

0226-9554 (imprimé)

1927-3924 (numérique)

Découvrir la revue

Citer ce document

Blanchet, A. (1982). Sept fantômes de l'Hôtel Manoir. Urgences, (5), 23-30.

https://doi.org/10.7202/025073ar d'utilisation que vous pouvez consulter en ligne.

https://apropos.erudit.org/fr/usagers/politique-dutilisation/ 


\section{ALAIN BLANCHET}

Sept fantômes de l'Hôtel Manoir 


\title{
MADAME BEAULIEU
}

\author{
Assis sous les néons rouges \\ nous jasons en mangeant des chips \\ madame Beaulieu est sur la trôle \\ elle parle d'amour \\ d'attentes vaines \\ des hommes virent autour \\ affables émoustillés \\ elle parle d'accord \\ de belles musiques \\ de bons talents \\ elle aime l'accordéon le violon \\ et la guitare électrique \\ son frère jouait dans les veillées \\ sa soeur est aux Ėtats \\ on fait des compliments \\ sur ses beaux costumes \\ les yeux complices \\ elle renvoie son énergie \\ avec toute sa fierté \\ et son courage de femme solitaire
}




\section{MADAME LAVOIE}

Elle longe la rampe de cuivre du même escalier principal gracieuse

madame Lavoie fonctionne les deux pieds sur son tapis dans son corridor le hockey l'emmerde et tous les autres sports télévisés c'est pour ça qu'elle s'occupe avec ses yeux de biche pétillante petite et gelée lorsque l'automne se risque sous ses jupes danseuse du ventre dans un bureau du gouvernement célibataire jusqu'à sa pension elle compile elle raye elle jase elle s'informe et les miroirs la fuient amitiés particulières haines tendres disponible en dehors des heures de repas où encore la nuit pendant qu'elle rêve elle erre quelquefois doucereuse chantant d'une voix aïgue qu'il viendra le jour 


\section{MOINEAU}

Pour lui la vie commence

à cinq heures du matin

avec la radio

une musique de ranch dedans

à la conquête de son territoire

la toilette est en face de sa chambre

de l'autre côté du corridor

il laisse toujours ses dents dans son tiroir

il a la bouche libre

comme un grand politicien drop-out

qui crie chaque jour sur la rue

en regardant passer les autos

en tenant sa blonde par la main

il reçoit les enfants de sa première femme

le soir au souper de temps en temps

projectionniste dans un cinéma de films de cul

aide-embaumeur par vocation

il joue des cuillers à manche de plastique

il voyage au dépanneur

avec ses bouteilles vides 


\section{JEAN-LOUIS}

Homme à tout faire mais pas trop vite à son rythme ancien soldat drogué sur le front de Normandie en avant des Anglais tout le monde sait ça refusant d'aller se battre tiré de force dans les tranchées bousté aux amphétamines revenu et marqué au fer rouge à quatre pattes ce matin 3:00 heures saoûl comme tous les samedis il prend sa douche froide puis saute sur sa chaudière le lundi

puis fait briller les vitrines des petits commerçants bourgeois en chantant des chansons de cowboys québécois perdus dans la plaine du bas St-Laurent et dans la bouche de son amie du dimanche qui range bien toutes ses casquettes dans son garde-manger 


\section{PETITO L'ITALIANO}

Un charmant restaurateur

réparateur de pizzas usagées

crie au plafond

lorsque le restaurant se vide à la fermeture qu'il déteste les poilus

et les pizzas

qu'il était ingénieur

dans son italie

qu'il est venu ici

pour bâtir des ponts

mais son diplôme ne valait rien

comme il fallait s'y attendre

les diplômes un jour ne valent plus rien

alors il lui restait la pizza

le ravioli le spaghetti et la lasagne

la fortune à portée de la main

qu'il a donc mise à la pâte

il roule en Volks

il fait l'amour avec sa serveuse

vers quatre heures et demie tous les matins

sur la table près du juke-box

avant de fermer boutique

et d'aller dormir

sur son matelas de mozarella 


\section{LE TCHOMME DENIS}

L'homme aux deux chiffres par jour

à la Calko

le jour comme opérateur de machine qui déraille le soir foreman des opérateurs

séparé et père d'une petite fille un bon yable

qui a navigué dans marine jusqu'en Amérique du Sud et qui navigue encore assis dans son bain il travaille pour deux pour en faire vivre deux sa fille et sa femme et survivre comme il peut en cherchant encore la femme sous son verre 


\section{GÉRARD}

Homme de maintenance

il roule en Météor 63

son collier de tournevis à portée

comme un révolver

il inspecte la bâtisse

il connaît toutes les pentures

les serrures des portes

la plomberie le chauffage

la menuiserie le nettoyage

diplômé de la vie

ex-réparateur de TV

pas pressé

il fait partie des meubles

son passe-partout dans la main

les cheveux gommés

un repère sûr

avec ses vingt ans de service

d'un administrateur à l'autre

il hait tous les notaires 